\title{
The role of TNF in diverse pathologic processes
}

Steven L. Kunkel ${ }^{1}$, Robert M, Strieter ${ }^{2}$, Steven W. Chensue ${ }^{1}$, Darrel A. Campbell ${ }^{3}$ \& Daniel G. Remick ${ }^{1}$

${ }^{1}$ Department of Pathology; ${ }^{2}$ Department of Internal Medicine; ${ }^{3}$ Department of Surgery, University of Michigan, Medical School, 1301 Catherine Road, Ann Arbor, Michigan 48109-0602, USA

Key words: interleukin-1, interleukin-4, ischemia/reperfusion, macrophage, prostaglandin E, transforming growth factor-beta, transplant

Abbreviations: IL-1: Interleukin 1; $\mathrm{PGE}_{2}$ : Prostaglandin; TGE-beta: Growth Transforming factor-beta.

\section{Introduction}

There is little doubt that tumor necrosis factor received center stage attention in biomedical research circles during the 1980s. Interest in this cytokine was not restricted to molecular biologists in biotechnology firms, but included cell and molecular biologists and whole animal physiologists in disciplines as diverse as pharmacology, pathology and surgery. As scientific studies now enter the 1990 s, interest in this cytokine has yet to peak. The pleomorphic effects of TNF in both physiologic and immunologic systems are the driving forces behind much of the investigative excitement that surrounds this cytokine.

For example, while low levels of TNF may be involved in the maintenance of physiologic homeostasis, elevated levels of TNF, associated with normal inflammation, may represent nothing more than an increase in homeostatic levels. Intense inflammatory processes with subsequent tissue injury also have been associated with this cytokine, although the production of TNF in these cases appear to be both exaggerated and protracted. In the latter scenario, life threatening consequences may ensue. Thus, this cytokine has been shown to possess numerous functional activities at the systemic, tissue, or cellular levels depending upon the concentration of TNF being synthesized.

Interestingly, the widespread activity of TNF appears to be due to the equally widespread expression of TNF receptors on a variety of cells $[1,2]$. Tumor necrosis factor can interact with a variety of immune/inflammatory cells, including lymphocytes $[3,4]$, mononuclear phagocytes $[5,6]$, and neutrophils $[7,8]$, as well as non-immune cells, such as fibroblasts $[9,10]$, endothelial cells [11, 12], and epithelial cells [13]. Considering the wide array of non-transformed cells that are suspectible to non-lytic stimulation by TNF, it is not surprising that active research remains directed at understanding the function of this cytokine.

One avenue of intense investigation is directed as assessing the production of TNF by stimulatory agents that have physiologic significance and connecting this synthesis with in vivo pathophysiologic events. A second area of interest concerns the regulation of TNF at the cellular and molecular levels. Studies examining the regulation of TNF will prove to 
be especially important, as it now appears that TNF is a proximal mediator and plays a central role in cytokine networking. A phenomenon whereby one cytokine, such as TNF, can induce the expression of an additional cytokine and establish a cascade effect. Thus, the modulation of this early response polypeptide may have a great impact on the synthesis of more distal mediators.

In the following manuscript concepts and data are presented that explore the involvement of TNF in the diverse pathophysiologic events of ischemia/reperfusion injury and the rejection of a transplanted organ. Although the importance of TNF as a proximal mediator is apparent during ischemia/reperfusion injury, this polypeptide is nonetheless important in chronic delayed type hypersensitivity processes that are operative during transplant rejection. The importance of TNF in both acute and chronic immune/inflammatory mechanism underscores the importance of studying regulatory circuits that control the production of this mediator. A number of studies have shown that macrophagederived TNF can be regulated at either the transcriptional or posttranscriptional levels by a variety of compounds, including steroids, lipids and other polypeptides. The efficacy of these endogenous regulators on the production of TNF (in the context of acute and chronic disease states) will prove to be an exciting and worthy area of research.

\section{The in vivo significance of TNF}

To fully appreciate the in vivo significance of TNF one must examine the cytokine from a historic perspective. For some of the earliest cytolytic studies on TNF pre-dates modern investigations by a century. The experimental data generated by Dr. Coley and others demonstrated that specific bacterial products, including lipopolysaccharide (LPS), was of potential therapeutic value in the treatment of inoperable head and neck sarcomas. These insightful studies essentially showed that humans treated with LPS could generate a factor that would induce the necrosis of specific solid tumors. This general research theme was reassessed years later when Carwell et al. [14] discovered a tumor-lytic polypeptide in the blood of BCG immunized mice challenged with endotoxin. Both of these "early" studies were crucial in establishing the observation that the administration of LPS to an intact animal could contribute to cytotoxicity.

Subsequent studies soon capitalized on these observations and demonstrated that many of the physiologic effects of LPS are mediated via the synthesis and release of soluble TNF [15-18]. Support for the hypothesis that TNF was one of the major polypeptide mediators involved in the pathogenesis of bacterial sepsis soon gained momentum. In a number of in vivo models, either LPS or gram negative bacteria could induce a shock-like state characterized by hypotension, malaise, fever, and respiratory failure $[15,17,19,20]$. Histologically these experimental animals presented with renal tubular necrosis, ischemic changes in the small bowel, and pulmonary edema. Compelling data that supported the role of TNF in the above alterations were presented in passive immunization studies using antibodies directed against TNF [17,21]. In addition, the direct infusion of TNF into experimental animals was found to mimic many of the effects of LPS. The administration of TNF has been reported to induce a metabolic acidosis [22], decrease the partial pressure of carbon dioxide $[22,23]$, increase the stress hormones epinephrine, norepinephrine and glucagon [23] and alter glucose metabolism [23].

\section{The clinical importance of TNF}

Clinical studies have also established a provocative link between systemic TNF levels 
and septic states. In the seminal studies by Waage et al. [24, 25] TNF was found in the sera of patients with meningococcal septicemia and, the levels of TNF correlated with morbidity and mortality [25]. Unfortunately the treatment of septic shock is primarily supportive, as totally efficacious therapy remains an enigma. Past therapeutic approaches advocated the use of high dose steroids for the treatment of septic shock [26], but prospective studies demonstrated this protocol had no effect on the final outcome of the syndrome [27]. Mechanistic studies, as to why steroids would not be useful in treating disease states associated with LPSdependent increases in TNF, demonstrated that TNF is an extremely proximal mediator and therapy can not be delivered in time to negate its production [28]. The induction of TNF gene transcription and protein translation is now known to be a rapid event after LPS challenge [28, 29]. Steroid treatment can only control TNF gene expression if given prior to LPS challenge or simultaneously with the LPS. Thus, the clinical usefulness of steroid therapy in controlling LPS-dependent septic states appear to be of little value.

\section{TNF in ischemia/reperfusion injury}

Although TNF does appear to be involved in the pathologic alternations of sepsis, this disease state is not the only clinically important process in which TNF may have a leading role. Elevated levels of TNF appear to be involved in the inflammatory processes associated with other specific disease states, including diseases of parasitic origin [30], autoimmune joint disease [31], allograft rejection [32] and viral disease [33]. Increased levels of TNF have also been found in patients with HIV infection and in many cases the concentration of TNF correlates with the clinical course of the disease [33]. In addition, recent studies from our laboratory have demonstrated that this interesting cytokine is involved in the adverse changes that occur during ischemia/reperfusion [34]. Using an established model of lobar ischemia/reperfusion, rather than total hepatic ischemia, an ischemic insult to the liver was induced without inducing mesenteric venous hypertension. A microaneurysm clip was used in these studies to stop both portal venous and hepatic arterial blood flow to the 3 cephalad lobes of the liver, while the 3 caudal lobes retained normal portal and venous flow. This aspect of the rat model is important, as intestinal venous congestion was prevented which negated bacterial translocation from a potentially ischemic small bowel. As shown in Table 1, the levels of bioactive TNF found in the sera correlated with the length of ischemia. In these studies a catheter was positioned in the supra-hepatic vena cava in order to obtain immediate post-hepatic blood samples. Ninety minutes of ischemia proved to be of significant time to induce the synthesis of TNF. In subsequent kinetic analyses, TNF was monitored in the sera at specific time intervals post reperfusion. The peak in TNF levels were found to be variable as they reached a zenith by 3 hours post reperfusion. The peak concentration of TNF ranged between $9-141 \mathrm{pg} / \mathrm{ml}$ of rat serum. Pathology induced by the hepatic ischemia/reperfusion was identified as a neutrophilic sequestration with edematous changes in the lungs (Table 2). The histologic alterations in the lungs may not be too surprising considering that the next vascular bed past the liver is in

Table 1. Kinetics of mean plasma TNF production following various periods of ischemia and reperfusion.

Tumor necrosis factor $(\mathrm{pg} / \mathrm{ml})$

\begin{tabular}{lllllllll}
\hline $\begin{array}{l}\text { Ischemia } \\
\text { time } \\
\text { (minutes) }\end{array}$ & \multicolumn{10}{c}{ Reperfusion time in minutes } \\
\hline 45 & 30 & 45 & 60 & 90 & 120 & 180 & 210 \\
\hline 60 & 2.0 & 5 & - & - & - & - & - & - \\
75 & - & - & - & - & - & - & - & 10 \\
90 & 5.0 & 2.0 & 2.0 & 2.0 & 18 & 20 & 42 & - \\
\hline
\end{tabular}


Table 2. Pathologic parameters assessing lung injury following 90 minutes partial hepatic ischemia and various reperfusion times.

\begin{tabular}{lll}
\hline $\begin{array}{l}\text { Reperfusion time } \\
\text { hours }\end{array}$ & \# RBC/Alveolus & $\begin{array}{l}\text { Permeability } \\
\text { index }^{\mathrm{a}}\end{array}$ \\
\hline 0 & - & 0.1 \\
1 & - & - \\
3 & 2 & 0.3 \\
6 & 4 & 0.4 \\
9 & - & 0.6 \\
12 & 24 & 0.55 \\
\hline
\end{tabular}

apermeability index was determined by monitoring the influx of ${ }^{125}$ I-labelled serum albumin into the lungs.

the lung. Therefore, this organ is in a location to fully receive the impact of mediators released down stream. This observation was of great interest, since the pulmonary injury post hepatic ischemia/reperfusion mimicked the pattern of injury following direct intravenous administration of recombinant TNF to rats. As previously reported [35] recombinant TNF induces punctate pulmonary hemorrhage associated with vascular permeability changes and neutrophil adhesion. Interestingly, pretreatment of rats prior to ischemia/ reperfusion with neutralizing antibodies dramatically reduced the pulmonary injury pattern. The anti-TNF antibody therapy reduced the lung permeability changes from a mean permeability index of 0.6 to 0.2 $(\mathrm{p}<0.05)$ using preimmune sera as compared to anti-TNF sera, respectively. In addition to salvaging the lung, the antibody treatment significantly decreased the pathology of the liver itself. This was identified as a maintenance of hepatocyte integrity and a reduction of neutrophilic infiltrates.

Although the cellular source of TNF in the ischemia/reperfusion model has not been identified, it is likely that the Kupffer cells (fixed liver macrophages) are the source of this cytokine. Past studies have shown that cultured rat Kupffer cells can be stimulated to produce significant amounts of TNF [36]. Since the Kupffer cell population in the liver represents a significant macrophage popula- tion, the production of inflammatory mediators by these cells could be formidable. The production of systemic TNF during ischemia/ reperfusion could account for much of the pathophysiology associated with this injurious process.

\section{TNF associated with transplant rejection}

It is becoming clear that TNF is a proximal mediator that may influence a number of important pathologic events. The above studies exemplify this observation, as TNF is generated rapidly during ischemia/reperfusion injury. Yet, the consequence of acutely generated TNF on disease states that become chronic is not clear. For example, transplant tissues are subjected to severe ischemic insults during the course of many hours. The effect of proximal TNF production on long term organ survival may be an important issue, as this cytokine may set in motion a cascade of events that are manifested at later time points. In an attempt to examine the role of TNF in such a setting, an allograft heart transplant model was established in HLA mismatched rats. A heart from a brown Norway rat was grafted into the carotid vasculature of a Lewis rat. In this model normal rejection occurs at approximately 7 days. At this time point, the donor heart exhibits the classic histology of a cell-mediated, delayed type hypersensitivity reaction. A one time injection of anti-TNF antibody to the rats, at time of heart transplant, prolonged the graft survival 2-3 fold. Instead of rejecting the graft at day 7 , the graft lasted until approximately day 16 . The therapeutic efficacy of the antibody treatment was also observed when administration was delayed for 24-36 hours. Interestingly, a immunohistochemical analysis for antigenic TNF in the donor heart at day 6 , in nontreated animals, revealed an intense staining pattern for TNF (Figure 1). Clearly demonstrating that TNF is present in the graft during the actual rejection. 


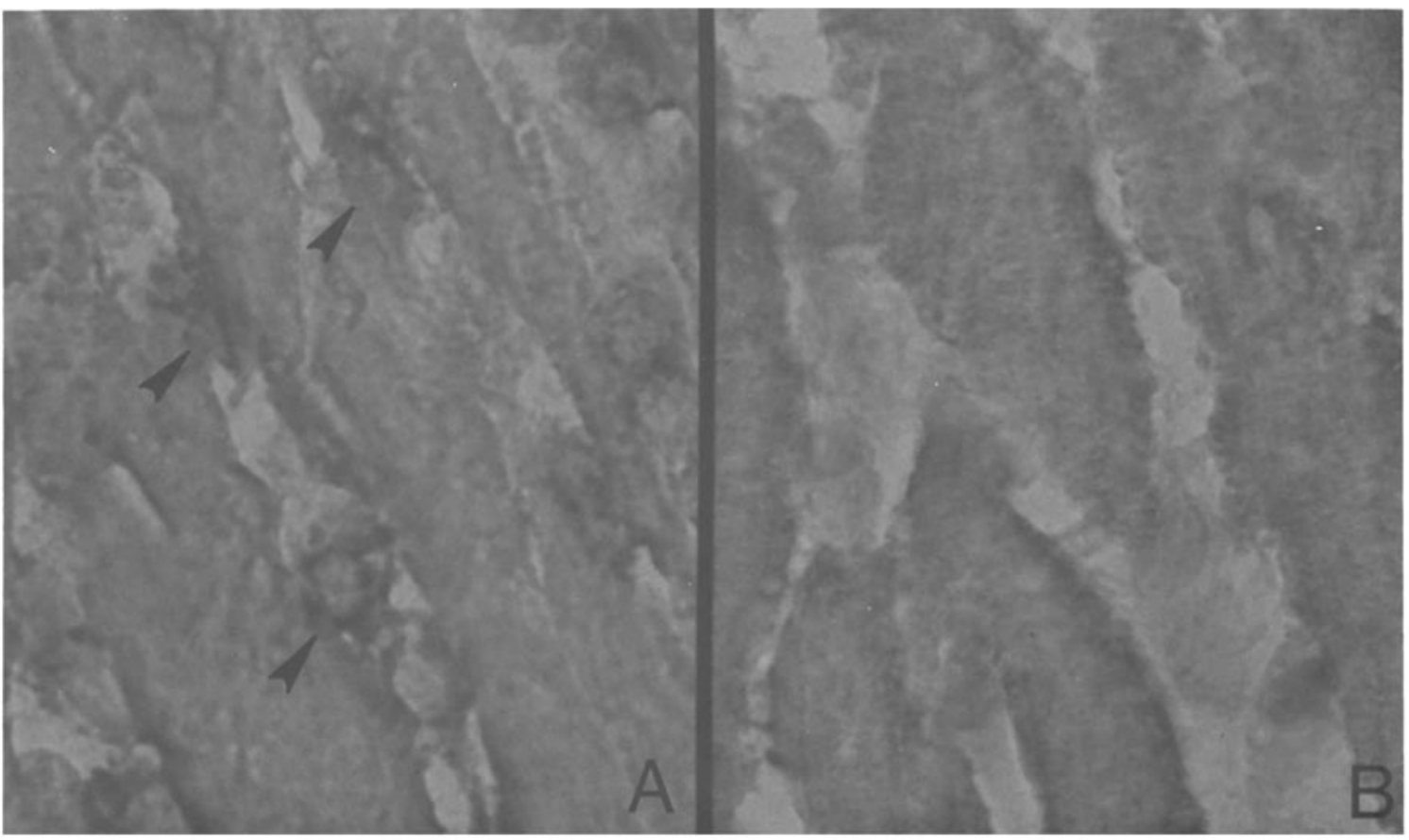

Fig. 1. Immunohistochemical analysis of rat heart 6 days post transplant. In both A and B a large inflammatory cell infiltrate can be seen. Frame $A$ is stained with specific antibody to rodent TNF, Frame B is stained using preimmune sera. The arrows point out cells positive for TNF.

Additional studies will be needed to determine if continued antibody infusion will prove to be more efficacious than a one-time bolus injection. These findings both support and expand previous reports that TNF is important in both delayed type hypersensitivity reactions and allograft rejection [32, 37].

TNF assumes an additional, important role in aspects of transplant immunology. Patients who are actively rejecting allografts will often be treated with the antibody OKT 3 , which effectively eliminates the $\mathrm{CD} 3$ positive cells from the circulation. Administration of this antibody causes significant patient distress with the development of fever, chills, rigors, headaches, and gastrointestinal distress. This same constellation of symptoms is often observed after giving exogeneous, recombinant TNF to human patients [38]. Two recent reports have indicated that there are transient, marked elevations of circulating TNF following OKT 3 therapy $[39,40]$. We have also documented the appearance of circulating TNF under these circumferences. Three patients who were rejecting their renal allografts received OKT 3 therapy; 2 of these developed detectable levels of TNF in the peripheral circulation shortly after the first injection. Interestingly, none of these patients developed symptoms after the second injection, and no TNF was detectable in the peripheral blood. These data provide further insight into the pathophysiology of endogeneous TNF production.

\section{Conclusion}

It is becoming increasingly apparent that variations in the quantity and spectrum of cytokines that are produced locally and/or systemically are important to the overall pathophysiology of the immune reaction. This general concept has proven useful in 
assessing the multiple changes induced during sepsis and shock-like states, but has not been thoroughly explored in other pathologic processes. In the above studies we have examined the role of TNF in two diverse states. In an animal model of hepatic ischemia/reperfusion, TNF appears to be generated very early during reperfusion and is instrumental in inducing injury in tissue distal to the liver. The lungs appear to be especially susceptible to pathologic alterations due to hepatic ischemia/reperfusion and the ARDS-like syndrome associated with some post-liver ischemic events may have a TNF component. Tumor necrosis factor also appears to be important in the alterations that occur during the rejection of transplanted organs. There is little doubt that ischemia/reperfusion is unavoidable during the transplant process and this may lead to TNF induced alterations. It is of great therapeutic interest that neutralizing antibody to TNF can ameliorate some of the adverse effects of these disorders. Finally, it is worthy to study endogeneous mechanisms that may account for the "normal" regulation of TNF. Natural mediators, such as $\mathrm{PGE}_{2}$, TGF-beta, and IL-4 are all logical candidates that may have potential clinical efficacy. Continued research directed at understanding this fascinating polypeptide mediator is needed to fully identify its role in health and disease.

\section{Acknowledgements}

We acknowledge the secretarial excellence of Suzanne Miller. This work was supported in part by NIH grants HL02401, DK38149, HL31963, and HL35276.

\section{References}

1. Hohmann HP, Remy $R$, Brockhaus $M$, van-Loon AP. Two different cell types have different major receptors for human tumor necrosis factor (TNF alpha). J Biol Chem 1989; 264: 14927-34.
2. Smith RA, Baglioni C. Multimeric structure of the tumor necrosis factor receptor of HeLa cells. J Biol Chem 1989; 264: $14646-52$.

3. Peetre C, Gullberg U, Nilsson E, Olsson I. Effects of recombinant tumor necrosis factor on proliferation and differentiation of leukemic and normal hemopoietic cells in vitro. J Clin Invest 1986; 78: 1694-703.

4. Jelinek DF, Lipsky PE. Enhancement of human B cell proliferation and differentiation by tumor necrosis factor alpha and interleukin-1. J Immunol 1987; 139: 2970-81.

5. Bachwich PR, Chensue SW, Larrick JW, Kunkel SL. Tumour necrosis factor stimulates interleukin-1 and prostaglandin $E$ production in resting macrophages. Biochem Biophys Res Comm 1986; 136: 94-101.

6. Phillip R, Epstein L. Tumor necrosis factor as immunomodular and mediator of monocyte cytotoxicity induced by itself, gamma interferon, and interleukin-1. Nature 1986; 323: 86-91.

7. Larrick JW, Graham D, Toy K, Lin LS, Senky G, Fendly BM. Recombinant tumor necrosis factor causes activation of human granulocytes. Blood 1987; 69: 640-52.

8. Shalaby MR, Aggarwal BB, Rinderknecht E, Svedersky LP, Finkle BS, Palladino MA. Activation of human polymorphonuclear neutrophil functions by interferon-gamma and tumor necrosis factor. J Immunol 1985; 135: 2069-78.

9. Strieter, RM, Phan SH, Showell HJ, Remick DG, Lynch JP, Genord M, Raiford C, Eskandari M, Marks R, Kunkel SL. Monokine induced neutrophil chemotactic factor gene expression in human fibroblasts. J Biol Chem 1989; 264: 10621-6.

10. Van Damme J, Dieckmann B, Simpson J, Rubira MR, Cayhas S, Vink A, Billiau A, van Snick J. Identification of the human $26-\mathrm{Kd}$ protein, interferon beta- 2 as a $B$ cell hybridroma/plasmacytoma growth factor induced by interieukin-1 and tumor necrosis factor. J Exp Med 1987; 165: $914-23$.

11. Strieter RM, Kunkel SL, Showell HJ, Remick DG, Phan SH, Ward PA, Marks R. Endothelial cells gene expression of a neutrophil chemotactic factor by TNF, IL-1, and LPS. Science (Wash DC) 1989; 243: 1467-9.

12. Pohlman TH, Stanness KA, Beatty PG, Ochs HD, Harlan $\mathrm{JM}$. An endothelial cell surface factor(s) induced in vitro by LPS, IL-1, and TNF-alpha increases neutrophil adherences by a CDW 18-dependent mechanism. J Immunol 1986; 136: $4548-54$.

13. Elner VM, Strieter RM, Elner SG, Kunkel SL. Human retinal pigment epithelial cells produce neutrophil chemotactic factor in response to IL-1, TNF, and LPS. Am J Pathol 1990 (in press).

14. Carswell EA, Old LJ, Kassel RL, Green S, Fiknore N, Williamson B. An endotoxin-induced serum factor that causes necrosis of tumors. Proc Natl Acad Sci USA 1975; 72: $3666-70$.

15. Beutler B, Cerami A. Cachectin and tumor necrosis factor as two sides of the same biological coin. Nature 1986; 320 : $584-9$.

16. Beutler B, Mahoney J, LeTrang N, Pekala P, Cerami A. Purification of cachectin, a lipoprotein lipase-suppressing hormone secreted by endotoxin-induced RAW-264.7 cells. J Exp Med 1985; 161: 984-91. 
17. Beulter B, Milsark IW, Cerami A. Passive immunization against cachectin/tumor necrosis factor protects mice from lethal effects of endotoxin. Science 1985; 229: 869-73.

18. Tracy KJ, Beutler B, Lowrey SL, Merryweather J, Wolpe S, Milsark IW, Hariri RJ, Fahey TJ, Albert JD, Shires GT, Cerami A. Shock and tissue injury induced by recombinant human cachectin. Science 1986; 234: 470-5.

19. Gilbert RP. Mechanisms of the hemodynamic effects of endotoxin. Physiol Rev 1960; 40: 245-68.

20. Morgan HR. Pathologic changes produced in rabbits by a toxic somatic antigen derived from Eberthella typhosa. Am J Pathol 1942; 135 -43.

21. Mathison JC, Wolfson E, Ulevitch RJ. Participation of tumor necrosis factor in the mediation of gram negative bacterial lipopolysaccharide-induced injury in rabbits. $\mathrm{J}$ Clin Invest 1988; 81: 1925-38.

22. Kettelhut IC, Fiers W, Goldberg AL. The toxic effects of tumor necrosis factor in vivo and their prevention by cyclooxygenase inhibitors. Proc Natl Acad Sci USA 1987; 84: 4273-81.

23. Tracey KJ, Lowrey SL, Fahey TS, Albert JD, Fong Y, Hesse D, Beutler B, Monague KR, Calvano S, Wei H, Cerami A. Cachectin/tumor necrosis factor induces lethal shock and stress hormone responses in the dog. Surg Gynecol Obstet 1987; 164: 415-23.

24. Waage A, Espevik T, Lamvik J. Detection of tumour necrosis factor-like cytotoxicity in serum from patients with septicaemia but not from untreated cancer patients. Scand J Immunol 1986; 24: $739-46$

25. Waage A, Halstensen A, Espevik T. Association between tumour necrosis factor in serum and fatal outcome in patients with meningococcal disease. Lancet 1987 ; $: 355-$ 7.

26. Schumer W. Steroids in the treatment of clinical septic shock. Ann Surg 1976; 184: 333-41.

27. Sprung CL, Caralis PV, Marcial EH, Pierce M. The effects of high-dose corticosteroids in patients with septic shock. A prospective, controlled study. N Engl J Med 1984; 311 : $1137-40$.

28. Remick DG, Strieter RM, Lynch JP, Nguyen D, Eskandari M, Kunkel SL. In vivo dynamics of murine tumor necrosis factor-alpha gene expression. Kinetics of dexamethasone-induced suppression. Lab Invest 1989; 60: 766 71.

29. Spengler RN, Spengler M, Lincoln P, Remick DR, Strieter RM, Kunkel S. Dynamics of dibutyryl cyclic AMP and Prostaglandin E-mediated suppression of lipopolysaccha- ride-induced tumor necrosis factor alpha gene expression. Infect Immun 1989; 57: 2837-41.

30. Scuderi P, Sterling K, Lam K, Finley P, Ryan K, Ray C, Petersen E, Slymen D, Salmon S. Raised serum levels of tumor necrosis factor in parasitic infections. Lancet 1986; 2: $1364-5$.

31. Saxne T, Palladino MA, Heinegard D, Tatal N, Wollheim FA. Detecting of tumor necrosis factor alpha but not tumor necrosis factor beta in rheumatoid arthritis synovial fluid and serum. Arthritis Rheum 1988; 31: 1041-5.

32. Maury CJ, Teppo AM. Raised serum levels of cachectin/ tumor necrosis factor in renal allograft rejection. J Exp Med 1987; 166: 1132- 7 .

33. Lahdevirta J, Maury CP, Tepp AM, Rap H. Elevated levels of circulating cachectin/tumor necrosis factor in patients with acquired immunodeficiency syndrome. Am J Med 1988; 85: 289-91.

34. Colletti LM, Remick DG, Burtch GD, Kunkel SL, Strieter RM, Campbell DA. The role of tumor necrosis factor in the pathophysiologic alterations following hepatic ischemia/reperfusion injury in the rat. J Clin Invest 1990 (in press).

35. Remick DG, Kunkel RG, Larrick JW, Kunkel SL. Acute in vivo effects of human recombinant tumor necrosis factor. Lab Invest 1987; 56: 583-90.

36. Magilavy DB, Rothstein JL. Spontaneous production of tumor necrosis factor alpha by Kupffer cells of $\mathrm{MRL} / \mathrm{lps}$ mice. J Exp Med 1988; 168: 789-94.

37. Lowry RP, Blais D. Tumor necrosis factor-alpha in rejecting rat cardiac allografts. Transplant Proc 1988; 20: 245 7.

38. Spriggs DR, Sherman ML, Michie H, Arthur KA, Imamura K, Wilmore D, Frei E III, Kufe DW. Recombinant human tumor necrosis factor administered as a 24-hour intravenous infusion. A phase I and pharmacologic study. JNCI 1988; 80: 1039-44.

39. Abramowicz D, Schandene L, Goldman M, Crusiaux A, Vereerstraeten P, De Pauw L, Wybran J, Kinnaert $P$, DuPont E, Toussaint C. Release of tumor necrosis factor, interleukin-2, and gamma-interferon in serum after injectino of OKT3 monoclonal antibody in kidney transplant recipients. Transplantation 1989; 47: 606-8.

40. Chatenoud L, Ferran C, Reuter A, Legendre C, Gevaert Y, Kreis H, Franchimont P, Bach JF. Systematic reaction to the anti-T-cell monoclonal antibody OKT3 in relation to serum levels of tumor necrosis factor and interferongamma. N Engl J Med 1989; 320: 1420-1. 